\title{
Mammary Tuberculosis : A Clinical Experience on 50 Cases
}

\author{
Md Matiar Rahaman Khan ${ }^{*}$ \\ Anupam Barua ${ }^{2}$ \\ Md Nuruddin Tarek ${ }^{3}$ \\ Md Abdur Rouf ${ }^{4}$ \\ ASM Ahsanul Karim ${ }^{4}$ \\ Md Nur Hossain Bhiyan ${ }^{5}$ \\ Tapan Bhattacharjee ${ }^{6}$ \\ Md Nizamuddin ${ }^{6}$ \\ 'Department of Surgery \\ Cox's Bazar Medical College \\ Cox's Bazar, Bangladesh. \\ ${ }^{2}$ Department of Medicine \\ Chittagong Medical College \\ Chittagong, Bangladesh. \\ ${ }^{3}$ Department of Medicine \\ Chittagong General Hospital \\ Chittagong, Bangladesh. \\ ${ }^{4}$ Department of Medicine \\ University of Science \& Technology, Chittagong (USTC) \\ Chittagong, Bangladesh. \\ ${ }^{5}$ Department of Surgery \\ Chittagong Medical College \\ Chittagong, Bangladesh. \\ ${ }^{6}$ Department of Anaesthesiology \& ICU \\ Chittagong Medical College \\ Chittagong, Bangladesh.
}

${ }^{*}$ Correspondence to:

\section{Dr. Md Matiar Rahman Khan}

Senior Consultant

Department of Surgery

Cox's Bazar Medical College

Cox's Bazar, Bangladesh.

Mobile : +8801819324177

E-mail:mrk1964@yahoo.com

w w w. c m o s h m cj.or g

\begin{abstract}
Mammary tuberculosis is a rare entity in western countries but a continuing problem in endemic areas like Bangladesh. Its clinical patterns and treatment strategies are changing day by day. In this study we showed our clinical experience on 50 cases of mammary tuberculosis. This is a prospective nonrandomized observational descriptive study. A total of 50 consecutive adult female patients with no other co morbid diseases and who were diagnosed cytologically or histologically as case of mammary tuberculosis were enrolled in the study over a period of 04 years since 2006 to 2010 in general surgical unit of Chittagong Medical College Hospital and Chittagong general hospital. The average ages of presentation were 38 years. $\operatorname{Ten}(20 \%)$ patients were lactating at the time of presentation and $\operatorname{six}(12 \%)$ patients were nulliparious. $40(80 \%)$ patients had breast lump at presentation. Among them $20(40 \%)$ presented with multiple sinuses with lump,10(20\%) had abscess with lump,05(10\%) had abscess drainage scar with underlying lump and 05(10\%) presented with isolated breast lump.06(12\%) presented with multiple sinuses with abscess formation. Another 04(8\%) patients had multiple sinuses only at presentation. Ten $(20 \%)$ had constitutional symptoms in the form of fever, weight loss and night sweat. Twenty (40\%) had axillary lymphaedenopathy in association with breast lesion. Diagnosis were confirmed by cytological and or histological findings of epitheloid granulomas.All patients were given antitubercular chemotherapy ( 9 months regimen) in combination with surgical intervention (45 out of 50 cases) as necessary in the form of excision of masses, incision and drainage of abscess and sinectomy. Mammary tuberculosis is a continuing problem in developing countries. Presentation may mimic benign lesion or carcinoma of the breast. Diagnosis can be made on high index of suspicion in endemic areas. Cytological or histological findings of granulomatous inflammation consisting of caseation necrosis, epitheloid cell and Langhans giant cell can give definitive diagnosis. Treatment is by anti tubercular chemotherapy with or without surgical intervention where necessary.
\end{abstract}

Key words: Mammary tuberculosis; carcinoma; antitubercular chemotherapy.

\section{INTRODUCTION}

Mammary tuberculosis is a rare form of tuberculosis ${ }^{1,2,3}$. The first case of mammary tuberculosis was recorded by Sir Astley Cooper in 1829 who called it 'Scrofulous swelling of the bosom ${ }^{4}$. Since then case reports and reviews have been published at infrequent intervals mostly in western literatures ${ }^{3}$. Now many studies were published in various papers of the subcontinent ${ }^{3}$. The significance of mammary tuberculosis is due to its mistaken identity with breast cancer and pyogenic abscess 5 . Progress in antitubercular chemotherapy and proper isolation of patient has lead to a decline in the incidence of tuberculosis during the past few decades. Recently TB has increased in many industrialized countries due to increased number of immunocompromised and AIDS patients. As incidence of tuberculosis increase, an increase in extra pulmonary involvement can be expected ${ }^{6,7,8}$. 
Only 28 cases of Mammary tuberculosis were reported in Japan over a 15 year period ${ }^{9}$. The over all incidence of mammary tuberculosis is reported to be $0.1 \%$ of all breast lesions, while in developing countries it constituted approximately 3.0\% of surgically treated breast diseases ${ }^{10}$. Over the years since the first description of mammary tuberculosis in 1829, the incidence, clinical presentation, diagnostic tools and therapeutic modalities of breast tuberculosis has been gradually changing due to changes in the environment, socioeconomic conditions and worldwide concerted preventive programme on tuberculosis. So a time to time observation of cases of mammary tuberculosis is necessary to coup up with the changing clinical patterns and newer therapeutic approaches. In this study we expressed our clinical experience regarding clinical presentation diagnosis and treatment options on 50 cases of mammary tuberculosis.

\section{PATIENTS \& METHODS}

This is a prospective non randomized observational descriptive study. A total of 50 consecutive patients were enrolled in this study within a period of 04 years from 2006 to 2010. Study place were general surgical unite of Chittagong Medical College Hospital and Chittagong general Hospital. The inclusion criteria for the study were- adult female patients, had breast lump/s sinus/s or abscess/s and whose diagnosis were confirmed as mammary tuberculosis on the basis of clinical suspicion and cytological or histological findings of epitheloid granuloma. Male patients, patients below the age of 12 years and patients who had other co morbid diseases were excluded from the study. A well informed written consent for study was obtained from all patients in a separate consent form. Detail clinical information about individual patient including age, clinical presentations, duration of symptoms, lactational status, previous history of pulmonary TB and findings of relevant investigations like ESR, mantoux test and chest radiogram were recorded for all patients. FNAC were done for patients who had lump/s but no abscess or sinus. Cases with abscess or sinus with or without underlying lump had directly undergone open biopsy. Diagnoses were made by clinical suspicion and presence of chronic granulomatous inflammation consisting of caseation necrosis,epitheloid cell and Langhans giant cell in the cytological or histopathological slide prepared from the collected specimen. Photograph of breast with academically interesting lesion were taken for printing and publication purpose which was clearly explained to the patients and permission were taken. A nine months regimen of four drugs antitubercular therapy were given to all patients in combination with surgical intervention in the form of lumpectomy, incision drainage or sinectomy as necessary. The doses of drugs and duration of therapy were adjusted depending on the weight of the patient and clinical response to therapy respectively. A short course of flucloxacillin was given to those patients who needed surgical intervention. Data for each patient were recoded in a predesigned individual patients data record sheet.

\section{OBSERVATION \& RESULTS}

A total of 50 cases were diagnosed as mammary tuberculosis. Table: 1 showed 26(52\%) patients presented at age range 31-40 years and $14(28 \%)$ patients at $21-30$ years. The average age at presentation was 38 years.

Table 1 : Age specific distribution of the patients $(n=50)$

\begin{tabular}{lcc} 
Age range & No. of patients & $\%$ \\
$<20$ years & 03 & 6 \\
21-30 years & 14 & 28 \\
31-40 years & 26 & 52 \\
41-50years & 05 & 10 \\
51-60 years & 02 & 04 \\
$>60$ years & 0 & 0 \\
Total & 50 & 100 \\
\hline
\end{tabular}

Table 2 : Clinical presentation at study entry of mammary tuberculosis $(\mathrm{n}=50)$

$\begin{array}{lccccc}\begin{array}{l}\text { Clinical presentation at study entry } \\ \text { Multiple Sinus/s with underlying }\end{array} & \text { Right } & \text { Left } & \text { Bilateral } & \text { No of Patients } & \% \\ \text { breast lump } & 10 & 09 & 01 & 20 & 40 \\ \text { Breast lump with abscess } & 06 & 04 & 0 & 10 & 20 \\ \text { Abscess drainage scar with lump } & 02 & 03 & 0 & 05 & 10 \\ \text { Lump Only } & 3 & 2 & 0 & 05 & 10 \\ \text { Discharging sinus/s with no lump } & 02 & 02 & 0 & 04 & 8 \\ \text { Discharging sinus/s with abscess } & 03 & 03 & 0 & 06 & 12 \\ \text { Total } & 26 & 23 & 01 & 50 & 100\end{array}$

Duration of time between appearance of first symptom and presentation to us were varied from one week to two years with most patients presenting at 5-18 months latter after the onset of their first symptoms.

Table 3 : Showing additional clinical information at study entry.

$\begin{array}{lcc}\text { Clinical Information } & \text { Number } & \% \\ \text { History of PTB } & 03 & 06 \\ \text { Lactating at the time } & & \\ \text { of presentation } & 10 & 20 \\ \text { Nulliparous } & 06 & 12 \\ \text { Postmenopausal } & 02 & 04 \\ \text { Constitutional symptoms } & 10 & 20 \\ \text { Axillary lymphadenopathy } & 20 & 40\end{array}$

Table:2 showed A total of forty [80\%] patients presented with lump/ lumps either alone or in combination in with sinus, abscess or multiple scars. 


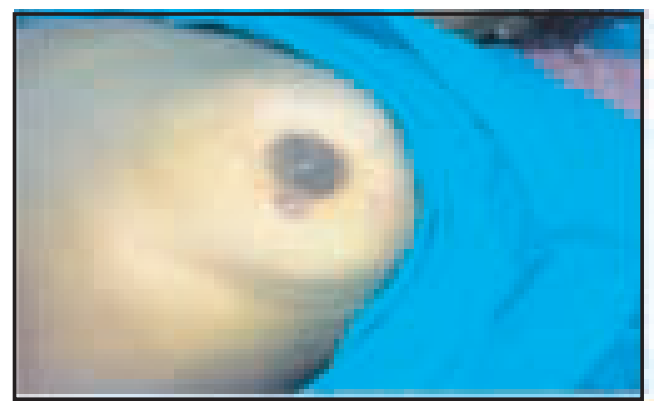

Figer 1: Mammary Tuberculosis (showing sinus with abscess)

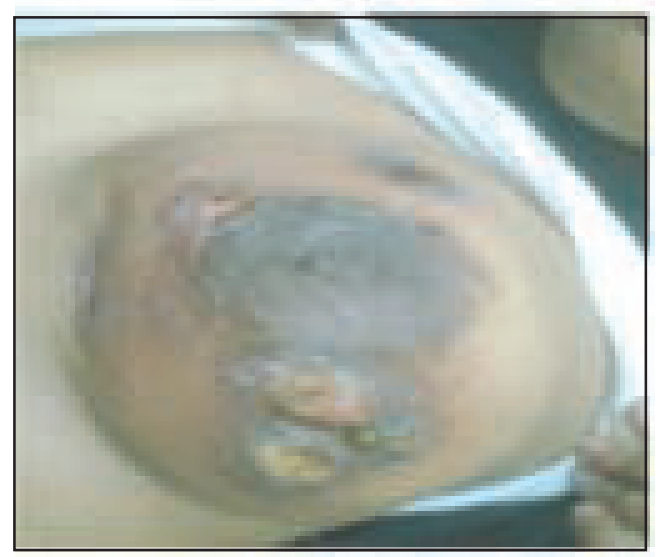

Figer 2 : Multiple abscesses with underlyng mass

Among them 20 patients (40\%) presented with sinus/sinuses in their affected breast along with underlying lump, ten patients (20\%) had lump with abscess formation during presentation. $05(10 \%)$ had isolated lump only. Another five patients had multiple abscess drainage scars with underlying mass. Six $(12 \%)$ cases presented with abscess with multiple discharging sinuses. Four (8\%) patients had multiple discharging sinuses with no lump at presentation. Right and left breast were involved almost equally (26 rt and 24 lt out of 50) and the disease was bilateral in one patient. Associated axillary Lymphadenopathy was present in 20 patients out of 50 (40\%).Table:3 showed 10 patients [20\%] were lactating at the time of presentation. Six [12\%] patients were nulliparous, two [4\%] were postmenopausal. History of pulmonary TB found in three cases. [Treated]. Ten [20\%] patients had constitutional symptoms in the form of fever, weight loss and night sweat.

Table 4: Anatomical distribution of lumps in the breast $(n=40)$

\begin{tabular}{lcc} 
Anatomical sites in the breast & no & $\%$ \\
Upper and outer quadrant & 20 & $50 \%$ \\
Upper and inner quadrant & 2 & $5 \%$ \\
Lower and outer quadrant & 1 & $2.5 \%$ \\
Lower and inner quadrant & 2 & $5 \%$ \\
Central subareoler area & 15 & $37.5 \%$ \\
Total & 40 & $100 \%$ \\
\hline
\end{tabular}

Table: 4 showed anatomical distribution of lumps in the breast. $50 \%$ of lumps(20 out of 40 ) were situated at the upper and outer quadrant of breast.37.5\%(15 out of 40$)$ of lumps were present in the central sub areolar region.

Investigation modalities used in this study were shown in table: 5 .
Table 5 : Distribution of patients depending on investigations modalities $(\mathrm{n}=50)$

\begin{tabular}{llrl} 
Investigation modalities & No & $\%$ & \multicolumn{1}{c}{ Results } \\
Chest radiogram & 50 & 100 & Active PTB 06(12\%) \\
ESR & 50 & 100 & Raised 40 (80\%) \\
Mantoux test & 50 & 100 & Positive 45 (90\%) \\
FNAC & 05 & 10 & Epitheloid granuloma 5(10\%) \\
Open biopsy & 45 & 90 & Epetheliod granuloma 45(90\%) \\
a)Excision of lumps including sinus & 20 & & \\
b)Incision drainage + excision biopsy & 10 & & \\
c)Biopsy from the abscess cavity & 6 & & \\
d)Excision of the mass & 5 & & \\
e)Wedge excision from the mouth & 4 & & \\
of the sinus & & & \\
Mammogram & 00 & 00 & 00 \\
USG of breast & 00 & 00 & 00 \\
Ziehl-Neehlson stain & 05 & 10 & Negative 05 \\
\hline
\end{tabular}

Patients with lump but no sinus or abscess were subjected to fine needle aspiration cytology [FNAC] 05cases. Open biopsy done in 45 patients. Among them wedge biopsy from the mouth of the sinuses were done in 04 cases, 10 patients having abscess with underlying lump had directly undergone excision of the lump and drainage of pus followed by biopsy, 06 patients who had sinus with abscess also had directly proceeded to drainage of pus and excision of sinus tract for histopathology, synectomy plus excision biopsy of mass were done in 20 cases, lumpectomy plus biopsy were done in 5 cases. Diagnosis of mammary TB was confirmed by a combination of clinical suspicion and cytological and or histopathological findings of epitheloid cell granulomas.

Discharges from the sinus were subjected to Ziehl-Neehlson staining in five patients only. All sample proved negative for acid fast bacilli.

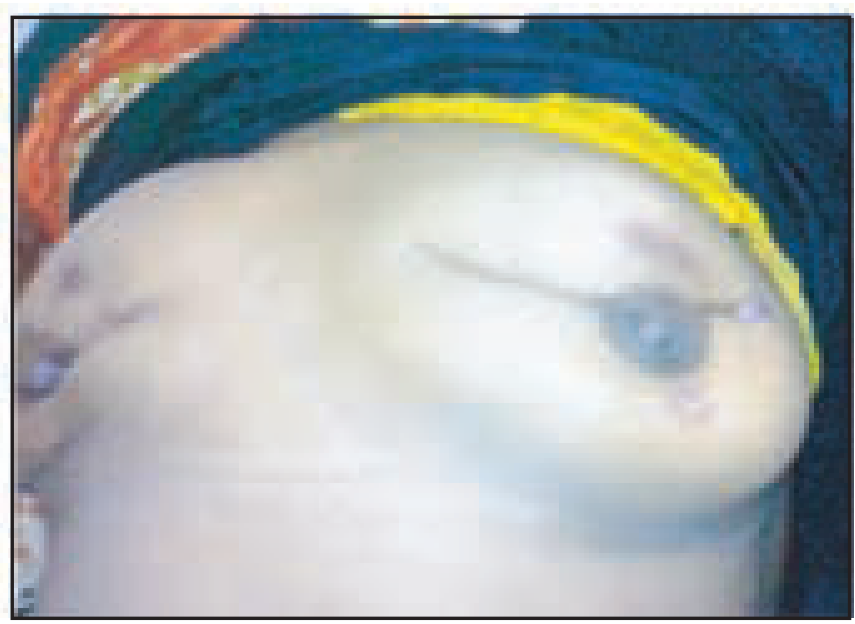

Figer 3: Bilateral mammary Tuberculosis (showing multiple sinuses)

Mantoux test were done in all the 50 patients 45 [90\%] out of 50 were found positive. Erythrocyte sedimentation rate were done in all cases raised ESR found in 40 cases[80\%].X-ray chest done for all patients active pulmonary TB were found in six patients but they had no symptoms of PTB at presentation. 
Table 6 : Therapeutics modalities of Mammary Tuberculosis $(n=50)$

\begin{tabular}{lcc} 
Therapeutic Modalities & No & $\%$ \\
Excision of the lump + ATT & 05 & 10 \\
Excision of mass + Sinectomy + ATT & 20 & 40 \\
Incision drainage of abscess + & & \\
Excision of the underlying lump +ATT & 10 & 20 \\
Incision drainage of abscess +ATT & 06 & 12 \\
Biopsy from the mouth of & & \\
the sinus + ATT & 04 & 08 \\
ATT Only & 05 & 10 \\
Total & 50 & 100 \\
\hline
\end{tabular}

All patients received antitubercular therapy comprising rifampicin, ionized, pyrazinamide and ethambutol for two months followed by rifampicin and isoniazid for another seven months. Doses were adjusted according to weight of the patients. Extension of antitubercular therapy from 12 to 18 months was required in 10 patients on the basis of their slow clinical response. Forty five patients (90\%) required surgical intervention in the form of excision of the mass including sinus tracts 20 patients, incision drainage and excision of mass 10 patients, incision drainage of the abscess 06 patients, synectomy 04 patients and lumpectomy 05 patients.

\section{DISCUSSION}

Most reported cases of mammary tuberculosis occur in developing countries where the incidence is $3 \%$ to $4.5 \%$ of all surgically treated breast disease ${ }^{10}{ }^{11}$. Mammary TB may be primary when no demonstrable tuberculosis focus exists, or secondary to a lesion elsewhere in the body ${ }^{11}$. Primary infection of the breast may occur through skin abrasions or through the duct openings on the nipple. Direct extension from the contiguous ribs is another possible mode of infection ${ }^{12}$. However it is generally believed that infection of the breast is usually secondary to a tuberculosis focus elsewhere which may not be clinically or radiologically apparent. Such a focus could be pulmonary or a lymph node in the internal mammary or axillary group ${ }^{12}$. Involvement of the breast in such cases is by haematogenous spread ${ }^{13}$. In our series six patients had evidence of active pulmonary tuberculosis while 20 had associated axillary lymphadenopathy. Khanna et al ${ }^{12}$. found 21 out of 52 patients had associated axillary lymphaedenopathy ${ }^{12}$. He said whether the axillary lymph node was the site of primary infection or secondary to the mammary tuberculosis is a debatable point.

Mammary tuberculosis usually affects the younger women usually between 20-40 year of age ${ }^{11}$. In present study most affected age group is $21-40(80 \%)$. It is relatively uncommon in older women and prepubertal girls ${ }^{11}$. Bilateral involvement is rare present in $3 \%$ cases shown in the paper of Banerjee et $\mathrm{al}^{13}$. In our series one patient had bilateral involvement.

Lactation is known to increase the susceptibility of the breast to tuberculosis due to increased vascularity ${ }^{13}$. Shinde et al found $7 \%$ of their patients to be lactating at the time of presentation $^{11}$. While Benerjee et al reported $33 \%$ of their patients to be lactating ${ }^{13}$.
In our series also $20 \%$ of the women were lactating at presentation. In these women, perhaps the stress of childbearing and increased vascularity of the breast facilitates infection and dissemination of the bacilli ${ }^{12}$.

Three forms of breast tuberculosis nodular, disseminated, and sclerosing, have been described ${ }^{14}$. Nodular pattern may be mistaken for a fibro adenoma or carcinoma ${ }^{15}$.

The disseminated form frequently leads to caseation and sinus formation. We observed 30 out of 50 patients had sinus formation almost nearer to that reported by Khanna et al(26 out of 52$)^{12}$. Sclerosing tuberculosis generally appears in older women. It is characterized by dense, fibrotic breast tissue and is slow growing, without suppuration.

The lump is the commonest presentation in breast tuberculosis ${ }^{16}$. Khanna et al showed $62 \%$ cases presented with lump ${ }^{12}$. Our observation was $40(80 \%)$.In our group of patients the most common site of involvement of lump was the upper and outer quadrant (20 out of 40 lumps) similar to that reported by Popli who reported the upper outer quadrant as the commonest quadrant of involvement and pointed out this is also the most common site of development of malignancy ${ }^{17}$.

Khanna reported subareolar disease as the most common site (19 of 54 cases) in his series ${ }^{12}$. our next common sites of involvement were central subareolar region ( 10 out of 40 lumps) which was nearer to that observed by khanna ${ }^{12}$ et al. In our series 20 out of 50 patients had sinus or sinuses in association with underlying breast lump and 10 patients had multiple sinuses with abscess formation. Almost similar observation found in the papers of khanna et al. (20 out of $52)^{12}$.

Radiological imaging modalities like mammography or ultrasonography are unreliable in distinguishing mammary tuberculosis from carcinoma. This is because of the variable pattern of presentation of such an inflammatory lesion. ${ }^{18}$ So in this series mammography and ultrasonography were not used as a diagnostic tools. We detected 06 cases of active PTB on chest radiogram and positive mantoux skin test in 45 cases. Chest radiogram may reveal active lesion in the lungs, but it is present only in few cases and mantoux skin test is usually positive in adults in endemic areas; therefore it is of no diagnostic value ${ }^{3}$.

The frequency of a positive stain for acid-fast bacilli (AFB) in the specimen has been reported to be lower and not essential for confirming the diagnosis ${ }^{2}$. None of the patients reported by $\mathrm{Khanna}^{12}$ or Kalac ${ }^{1}$ had positive stains for AFB. We send five samples of discharge from the sinus for AFB stain. All the samples were found negative for AFB.

Mammary tuberculosis can be diagnosed reliably by cytological or histological findings of epitheloid granulomas. Kakker et al could confidently diagnose mammary tuberculosis in $73 \%$ of patients on the basis of cytology ${ }^{2}$. Khanna $^{12}$ reported success rate of $100 \%$ in his series. Kakkar $\mathrm{S}$, et ${ }^{2}$ al reported that open biopsy from the lump, abscess wall or sinus tract almost always confirms mammary tuberculosis. Ten percent of our patients were diagnosed by cytology and $90 \%$ were diagnosed by histopathological methods. 
Anti tubercular chemotherapy is the backbone of treatment of breast tubercularsis ${ }^{19}$. In our series all patients received antitubercular chemotherapy and 45 patients had undergone surgical intervention in combination with ATT. In his series khanna $^{12}$ et al showed 24 out of 52 patients received surgical intervention along with ATT.The rate of surgical intervention is higher in our series than that of khanna et $\mathrm{al}^{12}$. Most of our cases presented to us 5 to 18 months after the development of their first symptoms due to this delay at presentation the lesion had already been complicated by abscess or sinus formation for which surgical intervention were mandatory. The cause of this late presentation was probably due to ignorance, poverty and conservative social customs.

\section{CONCLUSION}

Mammary tuberculosis is still prevalent in developing countries. Presentation may mimic benign lesion or malignancy of breast. Diagnosis is made on high index of suspicion in endemic areas. Cytology or tissue biopsy is required for definitive diagnosis. The anti-tubercular chemotherapy in combination with surgical intervention where necessary is the mainstay of treatment.

\section{DISCLOSURE}

All the authors declared no competing interest.

\section{REFERENCES}

1. Kalac N, Ozkan B, Bayiz H, Dusun Ab, Demirag F. Breast tuberculosis. Breast. 2002; 11(4): 346-349.

2. Kakkar S, kapila k, singMk, vermak, tuberculosis of the breast. A cytopathologic study. Acta Cytol 2000; 44:292-296.

3. Puneet, Satyendra K. Tiwary, Ritu Ragini, Sanjay singh sk. Gupta v.k. Shukla. Breast tuberculosis: Still common in India the internet journal of tropical medicine 2005; 2 (2).

4. Cooper A. Illustrations of the diseases of the breast. Part I. London: Longman, Rees, Orme, Brown and Green; 1829;73.

5. Tewri M, Shukla H.S Breast tuberculosis: diagnosis, clinical features and management. Indian J med Res 122, 2005; 103-110.

6. Wilson JP, Chapman SW. Tuberculosis mastitis. Chest 1990; 98; 1505-1509.

7. Hartstein M, Leaf HL. Tuberculosis of the breast as a presenting manifestation of AIDS, Clin Infect Dis 1992; 15; 692-693.

8. Al-Marri MR, Almoslesh A, Almoslmani Y, Primary tuberculosis of the breast in Qatar: ten year experience and review of the literature. Eur J Surg 2000; 166: 687-690.

9. Ohgak K, Mori T. Tuberculosis of the breast. Japanese Journal of Clinical Medicine 1998;56:1326-1328.

10. Schnarkowski P, Schmidt D, Kessler M, Reiser MF, Tuberculosis of the breast: US, mammographic, and CT findings. J Comput Assist Tomogr 1994; 18:970-971.

11. Shinde SR, Chandawarkar RY, Deshmukh SP. Tuberculosis of the breast masquerading as carcinoma: a study of 100 patients. Word J Surg 1995;19:379-381.

12. Khanna R, Prasanna GV, Gupta P, Kumar M, Khanna S, Khanna AK. Mammary tuberculosis: report on 52 cases. Postgrad Med J 2002; 78:422-424.

13. Banerjee SN, Ananthakrishnan N, Mehta RB, Prakash S. Tuberculosis mastitis: a continuing problem. World J. Surg. 1987; 11: 105-109.

14. Tabar L, Kett K, Nemeth A. Tuberculosis of the breast. Radiology 1976; 118:587-589.

15. del Agua C, Felipo F, Paricio J, Equizabal C, Delgado M. Tuberculosis of the breast as a pseudotumoral image. Breast J $2006 ; 12: 180$.

16. Alagrartnam TT. Ong GB.: Tuberculosis of the breast. Br. J Surg. 1980; 67:125-126.

17. Popli MB. Pictorial Essay: Tuberculosis of the breast. Ind J Radiol imag 1999;9:3:127-132.

18. Zandrino F, Monetti F, Candolfo N. Primary tuberculosis of the breast . A case report.Acta Radiol 2000; 41: 61-63.

19. Elmrabet F, Ferhati D, Amenssag L, Kharbach A, Chaoui A. Breast tuberculosis. Med Trop (Mars) 2002; 62: 77-80. 